\title{
Choque de gestão petista? Repensando a relação do PT com a reforma gerencial
}

\author{
PT's managerial shock? Rethinking the PT's \\ relationship with managerial reform
}

LEANDRO HEITICH FONTOURA*

RESUMO: Líderes petistas utilizando o slogan "choque de gestão" e defendendo políticas como avaliação de desempenho, premiação por resultados e transferência de serviços para organizações sociais não são encontrados facilmente, uma vez que são conceitos e instrumentos vinculados ao PSDB, seu principal adversário político. Este artigo apresenta administrações municipais petistas que revisam o tradicional discurso antirreforma do partido. São usados dados de uma pesquisa que buscou identificar prefeitos do PT alinhados aos princípios gerenciais. Para verificar a adesão de administrações petistas à APG, o estudo avaliou até que ponto implementaram políticas vinculadas a essa agenda. A pesquisa definiu cinco princípios básicos da APG: Planejamento; Meritocracia; Parcerias e contratualização; Participação e cidadania; Eficiência e modernização. Esses eixos contemplam 20 políticas de gestão, que formaram o questionário norteador das 10 entrevistas do estudo. A partir da pesquisa sobre a aplicação da agenda da APG em cinco administrações do PT, constatou-se que prefeitos da legenda, diante dos problemas urbanos das cidades, dos entraves da burocracia pública e do aumento das demandas sociais, aos poucos implementam políticas associadas aos adversários com a finalidade de tornar a máquina pública mais eficiente e oferecer serviços mais qualificados ao cidadão. A novidade trazida por este artigo é uma revisão do discurso petista. Essa mudança de postura não se dá sem tensionamentos com setores da legenda e do funcionalismo público, mas aponta para uma tentativa de revisão do posicionamento do partido.

PALAVRAS-CHAVE: Reforma do Estado; administração pública gerencial; PT; prefeituras; políticas públicas.

ABSTRACT: PT leaders using the slogan "managerial shock" and defending public policies such as performance evaluation, bonus for results and transfer of services to social organizations are not found easily, once this concepts and policies are linked to PSDB, its principal political adversary. This article shows PT mayors that make a review of PT's antireform speech. The article presents data from a search, which identified PT mayors lined up to

\footnotetext{
* Doutor em Ciência Política pela Universidade Federal do Rio Grande do Sul. E-mail: leandrofontoura@ hotmail.com. Submetido: 17/Abril/2018; Approved: 25/Junho/2018.
} 
managerial principles. To evaluate the accession of PT's local governments to Managerial Public Administration, this search evaluated Managerial Public Administration policies implementation. The search considers five principles of Managerial Public Administration: Planning; Meritocracy; Management Contracts and partnerships; Participation and citizenship; Efficiency and modernization. These principles include 20 policies, and these policies are part of the questionnaire used to interview 10 mayors and staff members of five PT local governments. It was found that, in contact with urban problems, public bureaucracy barriers and increasing of social demands, PT mayors are implementing policies to modernize the management and make it more efficient and effective to citizen. The novelty brought by this article is a review of PT's antireform speech. This posture change is characterized by constraints, tensions and conflicts with party groups and public servants. But it has signs pointing out to the construction of a new view on Managerial Public Administration by PT. KEYWORDS: Public sector reform; managerial public administration; workers' party; local government; public policies.

JEL Classification: J18; H11; H83

\section{INTRODUÇÃO}

Um prefeito petista usado o slogan "choque de gestão", outro ressaltando ser preciso "fazer mais com menos”. Essas não são cenas comuns na política brasileira, uma vez que a administração pública gerencial (APG), que deu origem a esses dois motes, se tornou uma bandeira de campanhas eleitorais e de governos do PSDB, principal adversário dos petistas. Em resposta, o PT passou a criticar essa escola de gestão, classificando-a como neoliberal e instrumento de redução dos serviços públicos. A disputa entre essas duas forças partidárias, que nas últimas décadas ocuparam o centro do palco político nacional, gerou uma dicotomia na construção de modelos para o setor público. Se de um lado o PT impulsionou a participação popular nas decisões como forma de ampliar o controle social e democratizar o Estado (Gugliano, 2005), de outro o PSDB apostou em ferramentas de gestão para tornar a máquina mais eficiente e os serviços mais qualificados. (Martins et al., 2006).

A novidade trazida por este artigo é uma revisão do discurso petista. A partir de uma pesquisa sobre a aplicação da agenda da APG em cinco administrações do PT, constatou-se que prefeitos da legenda implementam políticas associadas aos adversários com a finalidade de enfrentar os desafios urbanos atuais. Mais do que isso: chegam a sinalizar uma revisão do discurso petista em relação ao gerencialismo, que passa a ser visto como instrumento que pode ser politicamente orientado para atingir seus objetivos políticos e administrativos.

A formulação desse novo posicionamento é o foco do artigo, que está dividido em mais três seções. Nas duas próximas são apontadas a origem e as principais críticas à APG e as razões da oposição do PT à reforma. A seguinte apresenta um resumo dos resultados da pesquisa envolvendo administrações de Canoas (RS), São Bernardo do Campo (SP), Contagem (MG), São Carlos (SP) e Niterói (RJ), e a 
parte subsequente discute a relação desses prefeitos com a APG. A última seção é reservada às considerações finais.

\section{DO NEOLIBERALISMO DA NPM AO ESTADO SOCIAL DA APG}

Desenvolvido na esteira da crise do Estado do Bem-Estar Social, na década de 1970, e no esgotamento do modelo burocrático de administração, o gerencialismo foi implantado em diversos países antes de ser desenvolvido no Brasil. Sua paternidade é geralmente atribuída ao governo neoliberal de Margaret Thatcher (1979-1990), no Reino Unido, sob o título New Public Management (NPM). Ferlie et al. $(1999$, p. 26) constataram que, na sua origem, a NPM “[...] representou uma tentativa de tornar o setor público mais parecido com a iniciativa privada, guiado por noções rudimentares de eficiência." A principal marca do modelo era o caráter estritamente economicista, focado no corte de custos e de pessoal e no aumento da produtividade da máquina pública (Abrucio, 1998).

A necessidade de transformar o Estado, revendo o leque de funções públicas, espalhou-se pelo planeta ao longo da década de 1980. Governos passaram a reformar o aparato estatal com o objetivo de responder a diferentes pressões, entre as quais a globalização da economia, a ampliação do gasto público, o desenvolvimento de novas tecnologias de informação e comunicação, as distorções do modelo burocrático, a incapacidade de atender à demanda social e a perda de legitimidade do poder público (Pacheco, 2010a).

No Brasil, a onda gerencial chegou no início da década de 1990, em um momento de crise econômica, inflação alta, crescimento insatisfatório e de questionamento do tamanho do Estado desenvolvimentista. No governo de Fernando Henrique Cardoso (PSDB, 1995-2002) foi criado o Ministério da Administração Pública e Reforma do Estado (MARE), sob o comando do economista Luiz Carlos Bresser-Pereira, que tinha como meta colocar a gestão pública em novo patamar, em consonância com o processo mundial de reformas que ocorria havia mais de uma década. As propostas foram reunidas no Plano Diretor da Reforma do Aparelho do Estado (PDRAE) e na emenda constitucional n.19. O modelo proposto, batizado de Administração Pública Gerencial (APG), tinha como uma das metas superar os entraves da gestão burocrática. Enquanto essa última tem como princípio norteador a efetividade, a capacidade do Estado de garantir a lei, a primeira persegue a eficiência (Bresser-Pereira, 2010b).

Pelo diagnóstico do governo, o Estado brasileiro sofria de problemas fiscais e de uma administração burocrática caracterizada por ineficiência, morosidade, clientelismo e descompromisso. O modelo burocrático era hierarquizado, pesado e centralizador e marcado pelo excesso de regulamentos e pela uniformização de procedimentos na prestação de serviços (Ferrarezi, 2007). Nesse cenário, era limitada a possibilidade de resposta ágil às demandas sociais.

De acordo com Bresser-Pereira (2010b), “[...] a reforma gerencial de 1995, como as demais reformas dessa natureza, respondeu ao grande aumento do tama- 
nho do Estado [...]." A política de criação de estatais em vigor durante a ditadura militar havia espalhado empreendimentos públicos por todos os setores da economia, aumentando consideravelmente a presença do Estado (Martins, 1997). O PDRAE afirmava que o Estado brasileiro havia se desviado de suas "[...] funções precípuas para atuar com grande ênfase na esfera produtiva. Essa maciça interferência do Estado no mercado acarretou distorções crescentes neste último [...]" (Mare, 1995, p. 9).

Os reformadores acreditavam que seria possível fortalecer o Estado dentro de uma nova perspectiva de suas funções. O poder público passaria a atuar como regulador da economia e do mercado, deixando de ser "[...] o responsável direto pelo desenvolvimento econômico e social pela via da produção de bens e serviços, para fortalecer-se na função de promotor e regulador desse desenvolvimento" (Mare, 1995, p. 12).

Com base nesse cenário, o governo determinou uma mudança estrutural na máquina pública, e houve a transferência de algumas atividades exercidas pelo setor estatal para entidades apoiadoras do Estado. Os setores do núcleo estratégico e das atividades exclusivas do Estado permaneceriam sob o domínio estatal. O núcleo estratégico recebeu a responsabilidade de formular e avaliar as políticas públicas que passaram a ser desempenhadas por instituições qualificadas como agências executivas. Essa relação entre núcleo estratégico e agências executivas passou a ser mediada por contrato. Os serviços não exclusivos de Estado, por sua vez, poderiam ser prestados pela iniciativa privada ou por entidades do tipo "organização social" (Mattos; Siqueira, 2008).

Em relação ao setor de produção de bens e serviços, o modelo institucional previa a transferência das atividades para o mercado, por meio de privatizações. A reforma tinha como pressuposto a ideia de que as empresas estatais se tornariam mais eficientes e menos politizadas se controladas e administradas pelo mercado. A privatização e a transferência de serviços para organizações não estatais também tinham como alvo a cultura clientelista brasileira. Ao afastar determinados setores da esfera política, o governo estaria reduzindo o acesso a recursos de patronagem.

Do ponto de vista estrutural, a nova engenharia institucional estava baseada na noção de associar, de forma esquemática, formas distintas de domínio (estatal, público não estatal, corporativo e privado) a tipos distintos de atividades. Uma das principais mudanças foi o estímulo à formação de um espaço público não estatal. Com a transferência de atividades não exclusivas de Estado para o setor público não estatal, houve a multiplicação de Organizações Sociais (OS) e Organizações da Sociedade Civil de Interesse Público (Oscips). Essas são entidades sem fins lucrativos, públicas não estatais, financiadas e controladas pelo Estado por meio de termo de compromisso e contrato de gestão.

A literatura igualmente destaca a aprovação das emendas constitucionais $19 \mathrm{e}$ 20. Por meio dessas medidas, o governo estabeleceu limite para gastos com o funcionalismo, flexibilizou o regime jurídico de vinculação dos servidores e introduziu a eficiência como um dos princípios do direito administrativo em qualquer esfera do poder público. 
Bresser-Pereira (2010a, 2010b e 2008) reconhece que a reforma realizada na Grã-Bretanha inspirou suas ações. O ministro esteve na Grã-Bretanha para conhecer a experiência local. O autor afirma que, por conta do contexto histórico, de hegemonia do neoliberalismo, a escola que estava sendo criada na Grã-Bretanha passou a ser vinculada à proposta do Estado mínimo, mas, na sua opinião, em paralelo à noção de redução de despesas, havia um horizonte promissor de reformulação da gestão pública (Bresser-Pereira, 2010b). A recusa ao Estado mínimo também já estava expressa no PDRAE.

Bresser-Pereira afirma, primeiro, que o modelo da reforma brasileira é mais sofisticado teoricamente do que o implantado inicialmente por Thatcher no Reino Unido, segundo, que os governos trabalhistas na Nova Zelândia e na Austrália começaram reformas semelhantes, terceiro, que o principal objetivo da reforma, no Brasil, era tornar mais eficientes os grandes serviços públicos sociais e, assim, legitimar o Estado social, e, quarto, que a instituição internacional que se tornou responsável pelas reformas neoliberais foi o Banco Mundial, que pelo menos até 1998 se opôs à reforma gerencial com argumento de que antes era preciso completar a reforma burocrática (Bresser-Pereira, 1998).

Em uma conferência no Canadá em 2001, Bresser-Pereira afirmou que estava surgindo um novo Estado. No século XXI, avaliou ele, o Estado não será neoliberal nem social-democrático: será social-liberal. "Ele é social porque está comprometido para com os direitos sociais. É liberal porque acredita nos mercados e na concorrência mais do que neles cria o estado social-democrático" (Bresser-Pereira, 2001, p. 11).

Apesar das ressalvas, a reforma foi marcada por críticas que a vincularam ao modelo neoliberal. Dasso Júnior (2006) criticou o diagnóstico do governo, de que o Brasil padecia de uma crise de Estado provocada pelo desvio do poder público de suas funções básicas e entrada no setor produtivo. O problema do Estado brasileiro, na verdade, seria "[...] uma crise de legitimidade, resultado da insuficiência da representação derivada do modelo de democracia burguesa” (Dasso Júnior, 2006, p. 11). Em um cenário de fim da Guerra Fria e hegemonia do modelo capitalista, completa o autor, o Estado passou a representar uma barreira para a ampliação do lucro no setor privado. "Esse contexto, central para a ascensão do ultraliberalismo, exigiu reformas no Estado, com ênfase nas privatizações, em um primeiro momento, e na própria forma de gestão pública em um segundo momento" (Dasso Júnior, 2006 , p. 11). O autor também condena a mentalidade voltada para o mercado e a condução do Estado como se fosse uma empresa.

Os defensores da reforma afirmam que a inciativa não tinha perfil neoliberal porque buscava fortalecer o Estado, tornando-o mais capaz e eficiente. "A reforma gerencial não fazia parte do receituário do Consenso de Washington que procurou impor reformas neoliberais aos países em desenvolvimento" (Bresser-Pereira, 2010b, p. 14). Ainda como ministro, Bresser-Pereira já fazia distinção entre sua proposta para o Estado e a agenda neoliberal. Para ele, a direita quer a volta do Estado liberal do século XIX, "o que é ridículo, impossível, porque assim se perde a defesa dos direitos sociais. A esquerda e a social-democracia querem reformar o Estado. Um 
Estado menor, mais forte, menos privatizado e capaz de defender ou afirmar os direitos individuais, sociais e públicos (Bresser-Pereira, 1996, p. 9). Passados mais de 10 anos, o autor mantém o raciocínio: "A APG inspirou-se, sem dúvida, na administração de empresas, principalmente nas suas estratégias administrativas, mas isso não significa que tenha também adotado o lucro e outros conceitos do setor privado; o critério da administração pública é sempre o do interesse público" (Bresser-Pereira, 2010b, p. 21).

A literatura dos últimos 30 anos aponta para uma realidade complexa quando reformas baseadas nos primórdios da NPM são comparadas em nível internacional. Pacheco (2010a) mostra uma diversidade ideológica despontada após os primeiros passos da NPM. Reformas também foram feitas por governos trabalhistas, como na Nova Zelândia entre 1984 e 1990 ou na Austrália, de 1983 a 1996 (Pacheco, 2010a, p. 189). Ferlie et al. (1999, p. 41) já havia registrado que "não há uma convergência simples acerca de um modelo da NPM, mas sim que há uma variedade de opções à disposição”. Para Pacheco (2010a, p. 189), “[...] a agenda contemporânea gerencialista não pode ser tomada como sinônimo do NPM" da era Thatcher. Um dos argumentos da autora é a experiência dos países escandinavos, nações de longa trajetória social-democrata, na adoção e na adaptação de princípios gerenciais.

Independentemente das controvérsias, a passagem de Bresser-Pereira pela Esplanada dos Ministérios impulsionou um debate nacional a respeito do setor público, suas deficiências e formas de melhorar seu desempenho. Logo, as diretrizes da APG acabaram influenciando administrações estaduais e municipais por todo o país. Técnicos que atuaram na reforma na esfera federal migraram para estados e passaram a aprimorar instrumentos de modernização da máquina pública. Consultorias especializadas em gestão empresarial também passaram a oferecer serviços baseados nos preceitos da APG a prefeitos e governadores. Inicialmente, esses processos foram realizados em governos do PSDB, como o de Aécio Neves em Minas Gerais (2003-2010), que cunhou a expressão "choque de gestão". Com o passar do tempo, iniciativas semelhantes foram desenvolvidas em gestões de outros partidos, como a de Eduardo Campos (PSB), em Pernambuco (2007-2014).

Cresce nos estados o interesse por implantar políticas inovadoras, capazes de equalizar ajuste fiscal e ferramentas gerenciais e de melhorar os serviços públicos. Iniciativas como a transferência de serviços para OS e Oscips, a criação da carreira de gestor público e o desenvolvimento de sistemas informatizados destinados a controlar e a racionalizar o gasto foram reproduzidas em diferentes estados. Por outro lado, a introdução de modelos meritocráticos de incentivo ao funcionalismo e de instrumentos de fortalecimento da democracia e do accountability não teve o mesmo ritmo. Essa discrepância indica que as reformas nos estados não respeitam a uma fórmula única. Em cada unidade da federação, a realidade política e administrativa local impôs condições específicas para o avanço das mudanças, uma vez que impactam em processos políticos e estruturas arraigadas de poder (Abrucio; Gaetani, 2008).

Abrucio e Gaetani (2008) avaliam que o alastramento dos princípios da APG pelos estados acabou criando um "caldo de cultura" capaz de incentivar mudanças 
no setor público e fornecendo um "referencial geral de modernização". Com o tempo, esse novo modelo de gestão teria perdido o carimbo de iniciativa do governo Fernando Henrique e ficado mais livre das "brigas ideológicas". Mas nem todas.

\section{O PT DA OPOSIÇÃO AO PSDB ÀS CONTRADIÇÕES DE GOVERNAR}

O PT sempre viu a proposta de reforma como linha de frente do projeto neoliberal. No clima de guerra de torcidas que impera na política nacional, qualquer tentativa de reestruturar o Estado, na visão petista tradicional, estaria comprometida como política de direita e do PSDB. Esse posicionamento está sustentado em um tripé de caráter corporativista, ideológico e de antagonismo partidário. Para entender esses pilares e como se articulam, é preciso retomar a trajetória do partido.

A novidade representada pelo PT no sistema partidário brasileiro tem origem no seu enraizamento social. Fundada em fevereiro de 1980, no Colégio Sion, em São Paulo, a agremiação reunia o sindicalismo renascido nos estertores da ditadura militar (1964-1985), os movimentos sociais urbanos e rurais, grupos de esquerda de diversos matizes marxistas e alas ligadas à Igreja Católica (Ribeiro, 2008). Singer (2012) batiza esse sopro inicial petista de o "espírito de Sion", um movimento que se sentia portador e capaz de inaugurar uma nova República, sem compromissos com as tendências políticas tradicionais. A proposta de fundação do partido, avalizada em um Congresso dos Metalúrgicos, em 1979, pregava a criação de uma legenda "sem patrões", não "eleitoreira" e que organizasse os trabalhadores em torno da construção de uma sociedade mais justa, "sem explorados e exploradores" (Manifesto do PT, 2007).

Com o passar dos anos, cresce também a relação da agremiação com o funcionalismo público (Ribeiro, 2008). Sindicatos de servidores encontram no partido abrigo para a defesa de seus interesses e de suas ideias sobre políticas públicas. Há também nesse vínculo um apelo a uma relação pura, nascida de baixo: eram os próprios funcionários públicos e não as elites políticas que tomavam a frente das discussões sobre o que deveria fazer o Estado. O problema é que o estreitamento desses laços torna difícil enxergar onde os interesses corporativos passam a se impor sobre os coletivos, principalmente quando os primeiros se traduzem em grandes votações para agremiação. Um dos principais formuladores do PT, Tarso Genro reconhece esse impasse ao afirmar que as bancadas parlamentares de esquerda se tornaram uma "soma de posições corporativas do mundo do trabalho" (Genro, 2012). A relação da legenda com o funcionalismo é um dos três pilares que afastam o partido da APG, uma vez que o gerencialismo mexe com as estruturas sedimentadas na máquina pública.

Havia, nos anos iniciais petistas, uma recusa a tudo que representasse o status quo, e a constituição da identidade partidária se deu em oposição à política tradicional. No lugar do clientelismo, surge o Orçamento Participativo, a decisão coletiva sobre o destino dos recursos públicos. No lugar das alianças puramente eleitorais, nascem candidaturas puras - a maioria sem qualquer chance de vitória, mas 
disposta a marcar posição. No lugar do financiamento partidário via doações do setor econômico, legais ou ilegais, principalmente de empresas com contratos públicos, despontam sistemas alternativos, como a contribuição voluntária de militantes e a comercialização de símbolos da legenda. No lugar de decisões de cúpula, se formam mecanismos internos de democracia partidária. No espírito de Sion, não havia espaço para o velho patrimonialismo.

Nada mais previsível de esperar que, ao chegar ao poder, com a vitória de Luiz Inácio Lula da Silva em 2002, o espírito de Sion fosse romper com as práticas patrimonialistas. Mas não é o que ocorre. No governo Lula, o PT mergulha na política tradicional e emerge dela abraçado a todos os personagens que desprezou por anos, símbolos de um país no qual a marcha da burocratização racional não ocorre como previu Max Weber.

E pior: o escândalo do mensalão, em 2005, provoca a até então maior crise da história do partido e abala seriamente o governo. Sete anos depois, a antiga cúpula da legenda acaba condenada pelo Supremo Tribunal Federal por corrupção ativa e formação de quadrilha, acusada de comprar votos no Congresso. Uma ala da agremiação sai em defesa do grupo sentenciado, alegando que o julgamento foi político e que os ministros sucumbiram à pressão da imprensa, das classes dominantes e do projeto neoliberal. Outra parcela da sigla, ainda que com dificuldade de aceitar as condenações, prefere refletir sobre o episódio.

Em março de 2014, um novo escândalo, agora envolvendo desvios em contratos da Petrobras com grandes empreiteiras, volta a abalar o governo, agora de forma irremediável. A Operação Lava Jato, investigação da Polícia Federal que voltou a colocar importantes líderes petistas sob suspeita, foi um dos fatores que levou ao impeachment, em 2016, de Dilma Rousseff, sucessora de Lula. As apurações expuseram as relações entre a elite política brasileira e as grandes empreiteiras.

Além disso, balanços sobre os anos petistas no Planalto, escritos a partir de uma perspectiva de esquerda, passam a apontar contradições do governo. O PT havia chegado ao poder após anos de ferrenha oposição aos governos Fernando Collor e Fernando Henrique. Uma síntese do pensamento petista pode ser encontrada em Mercadante (2010). O autor afirma que o governo Fernando Henrique expandiu reformas econômicas voltadas a "[...] estabelecer a primazia absoluta do mercado e remover as restrições à inserção do país no processo de globalização [...]" (Mercadante, 2010, p. 78). Essa agenda, para o autor, foi realizada por meio de abertura comercial ampla e irrestrita, remoção das restrições à livre movimentação do capital estrangeiro, privatização das empresas e serviços públicos, fragilização da capacidade de regulação e apoio ao crescimento do Estado, desregulamentação da atividade econômica e abertura do sistema financeiro.

Críticos de extrema esquerda não enxergam tanta distinção entre as administrações de Fernando Henrique e Lula. Oliveira (2007) afirma que a gestão petista endossou a política econômica tucana e governou com o apoio de agremiações de direita, entre as quais PP e PMDB, e de grandes empresários reacionários. Em vez de fazer mudanças profundas no país, Lula decidiu combater a pobreza sem confrontar o capital, sem criar "inimigos de classe". A criação do Bolsa Família seria mais um 
ato simbólico, uma "revolução moral”, como a derrota do apartheid na África do Sul, do que uma real alteração na estrutura social brasileira. Alves (2013) classifica os governos Lula e Dilma como pós-neoliberais. Ainda que comprometidas com crescimento da economia, aumento de gastos públicos e distribuição de renda, analisa o autor, as gestões preservaram e reforçaram os pilares do Estado neoliberal.

O que teria acontecido no período entre a efervescente criação do PT e a chegada da agremiação ao Palácio do Planalto? O PT, no início dos anos 2000, não era mais o mesmo partido de duas décadas antes. Já refletia o "espírito do Anhembi”, elaboração de Singer (2012) para definir a legenda após o radicalismo ter sido domado pela realpolitik. O autor usa as categorias espírito do Sion e espírito do Anhembi para demonstrar as contradições internas petistas. Se a primeira alma traz o radicalismo de esquerda inicial, a segunda se refere à conformação da legenda aos preceitos do conservadorismo econômico. O espírito do Anhembi começou a ser concebido na derrota presidencial de 1989 e nasceu na divulgação da Carta ao Povo Brasileiro, em 22 de junho de 2002, pela qual o então candidato Lula se compromete com os pilares econômicos do governo Fernando Henrique e contraria as teses tradicionais do petismo.

Como manter o antagonismo no campo político é fundamental no embate pela hegemonia (Laclau \& Mouffe, 1985), a postura petista deve ser entendida em um contexto amplo, vinculado à trajetória da agremiação. Ao longo dos anos, o PT migrou do radicalismo de esquerda que marca pequenas siglas sem chances de sucesso eleitoral à maleabilidade exigida de quem deseja governar (Singer, 2012). A vitória de Lula sobre José Serra (PSDB) fazendo concessões ao conservadorismo econômico representou o coroamento dessa mudança. Para Singer (2012), o governo Lula enveredou para um reformismo fraco, capaz de provocar mudanças expressivas "onde o atraso deixava a pobreza intocada".

No plano ideológico, o PT ainda se define como uma organização que busca “construir o socialismo democrático" - um discurso voltado às bases partidárias nostálgicas de um passado marcado pela luta contra a ditadura militar (1964-1985) e pela utopia representada pelo mundo comunista. Na prática, a legenda está acomodada no centro do espectro político e atua na linha da social-democracia (Ribeiro, 2008). Nos governos Lula e Dilma, o reformismo tomou o lugar do socialismo. Mas, ao se aproximar tanto do rival político, restou ao PT sustentar a crítica à reforma do Estado como um dos elementos discursivos capazes de mantê-lo em posição antagônica em relação aos tucanos, o segundo pilar citado no início desta seção.

Contribuem para a manutenção desse discurso antirreforma resquícios da origem marxista de alas do partido, característica do pilar ideológico também já mencionado. Passadas mais de duas décadas da queda do Muro de Berlim e algumas rupturas internas que provocaram a criação de outras siglas mais à esquerda, como PSOL e PSTU, sobrevivem no PT correntes que desprezam a iniciativa privada. Esses grupos consideram que um governo com vocação popular e voltado ao atendimento de demandas sociais precisa assumir uma postura antimercado. E é assim então que os espíritos do Sion e do Anhembi dão as mãos contra a reforma gerencial. 


\section{O GERENCIALISMO EM PREFEITURAS PETISTAS}

Como o discurso petista contra a APG foi concebido há mais de duas décadas, em outro contexto histórico, é preciso avaliar sua atualidade ante os desafios administrativos constituídos ao longo dos anos. Esse foi o foco de uma pesquisa que buscou identificar prefeitos do PT alinhados aos princípios gerenciais.

Somando os dois turnos da eleição de 2012, o PT venceu em 639 municípios de todo o país. Quatro anos antes, o número havia sido 557. Diante de um cenário tão abrangente, encontrar prefeitos alinhados aos princípios da APG exigiu estratégia ampla de sondagem. A primeira iniciativa foi coleta de informações na internet. Foram vasculhados sites que poderiam revelar referências a respeito de gestões petistas. Ao mesmo tempo, foram examinados resultados de premiações oferecidas a prefeitos reconhecidos pela implantação de processos de inovação e de modernização da gestão, como as distinções concedidas pelo Movimento Brasil Competitivo (MBC). Foram procuradas fontes que, por conhecimento sobre gestão ou contatos profissionais, poderiam citar prefeitos com o perfil procurado.

Entre janeiro e março de 2015, foram realizadas 10 entrevistas com prefeitos e ex-prefeitos do PT e também com secretários ou ex-secretários municipais das áreas de Planejamento, Modernização da Gestão, Controle, Orçamento e Administração. As gestões pesquisadas são as seguintes:

Quadro 1: As gestões

\begin{tabular}{|l|l|c|}
\hline \multicolumn{1}{|c|}{ Prefeitos } & \multicolumn{1}{c|}{ Município/UF } & \multicolumn{1}{c|}{ Mandatos } \\
\hline Jairo Jorge da Silva & Canoas (RS) & $2009-2016$ \\
\hline Marília A. Campos & Contagem (MG) & $2013-2016$ \\
\hline Rodrigo Neves Barreto & Niterói (RJ) & $2009-2016$ \\
\hline Luiz Marinho & São Bernardo do Campo (SP) & $2009-2012$ \\
\hline Oswaldo Baptista Duarte & São Carlos (SP) & \\
\hline
\end{tabular}

Fonte: Elaborado pelo autor.

Para verificar a adesão das administrações à APG, foi preciso avaliar até que ponto implementaram seus princípios, que, desde os anos 1980, passaram por diversas fases e evoluíram por diferentes caminhos e contextos políticos e culturais (Ferlie et al., 1999; Pacheco, 2010). Para mensurar essa adesão, a pesquisa elencou 20 políticas de gestão vinculadas à agenda gerencial, compiladas a partir da literatura especializada internacional (Martins et al., 2006; OCDE, 2005; Jann \& Reichard, 2002; entre outros) e sistematizadas, a título de organização do estudo, em cinco princípios básicos da APG: Planejamento; Meritocracia; Parcerias e contratualização; Participação e cidadania; Eficiência e modernização. As 20 políticas e os seus princípios compuseram o questionário norteador das entrevistas, por tele- 
fone e por escrito, com questões estruturadas e semiestruturadas. O propósito foi o de reunir informações de uma forma multidimensional.

$\mathrm{O}$ cruzamento das entrevistas e de fontes documentais permitiu aprofundar o conhecimento sobre a relação das administrações com a APG. Os resultados podem ser resumidos da seguinte forma:

1 - Em relação ao Planejamento estratégico, todas as prefeituras utilizaram as principais ferramentas, incluindo programas estruturantes e gestão por metas e indicadores. Três tiveram auxílio de consultorias privadas. Destaca-se a aplicação, em Niterói e Contagem, do planejamento baseado na ideia de construir a "melhor cidade de se viver", recurso que evidencia preocupação com a continuidade administrativa para além do ciclo político. A inclusão de mecanismos de participação na elaboração do planejamento aparece em três, com destaque para São Bernardo do Campo, que realiza o PPA Participativo, modelo que vai além das exigências legais.

2 - O princípio da Meritocracia se mostrou um dos mais controversos por conta da resistência de servidores. As administrações agiram para ampliar formas de mensurar resultados e incentivar o aprimoramento profissional. A avaliação de desempenho foi adotada em três (Canoas, Contagem e São Carlos). A reestruturação de carreiras foi efetivada em quatro (Canoas, Contagem, São Bernardo do Campo e São Carlos). A remuneração variável só foi aprovada em Canoas.

3 - No eixo Parcerias, somente Contagem não firmou contratos com Organizações da Sociedade Civil de Interesse Público (Oscips), resultado que pode ter sido facilitado por tratar-se de legislação mais antiga. No caso das Organizações Sociais (OS), há menor adesão, foram aceitas apenas em Niterói e São Carlos, sob oposição do funcionalismo e de alas do PT. No caso das Parcerias Público-Privadas (PPPs), São Bernardo do Campo e São Carlos têm concessões do tipo em andamento. O número é baixo, mas ainda assim tem destaque por tratar-se de regramento recente, engenharia contratual complexa e custos altos.

4 - As cinco administrações implementaram ferramentas para ouvir a população, instrumentos de ampliação da transparência e sistemas informatizados para melhorar o atendimento ao cidadão. O Orçamento Participativo (OP) foi realizado em quatro, mas há sinais de seu "envelhecimento". Afora o fato de ser baseado em um longo ciclo de assembleias presenciais - modelo que destoa de um mundo cada vez mais conectado -, o OP enfrenta o surgimento de novas formas de participação, como a cultura colaborativa. Entre as prefeituras estudadas, há novos modelos digitais de participação.

5 - O princípio Eficiência e modernização tem como carro-chefe o ajuste fiscal. Niterói e Canoas são categóricas em assumir a realização dessa medida, atitude de duplo impacto: o primeiro, por se tratar de uma iniciativa de caráter impopular, e o segundo, por representar redução de gastos públicos que os petistas sempre acusaram os tucanos de fazer. Niterói chega a usar a expressão "choque de gestão" para definir as medidas emergenciais contra a crise. O prefeito de Canoas, Jairo Jorge da Silva, igualmente dá destaque para o ajuste nas contas, mas não chega a repetir o mote de Aécio. Em compensação, adotou uma variação local do bordão, “o fazer mais com menos”, popularizada no Rio Grande do Sul pela gestão de Yeda 
Crusius (PSDB) no Palácio Piratini (2007-2010). As outras três administrações confirmam ter reduzido custos e ampliado receitas visando ao equilíbrio nas contas. As demais políticas avaliadas (TI voltada à gestão; racionalização/redução da máquina; contrato com consultoria de gestão privada; e redução da burocracia) tiveram ampla aceitação.

\section{A VISÃO DOS PREFEITOS SOBRE A APG}

Entre as cinco administrações estudadas, Canoas e Niterói indicam maior engajamento aos princípios da APG, ao ponto de realizarem uma autocrítica ao discurso petista tradicional, defenderem o ideal gerencialista e lançarem uma plataforma de integração dessa agenda às gestões do partido. Nada disso significa abrandar a polarização com o PSDB. Há uma clara intenção em demonstrar que o partido adversário usa o gerencialismo baseado em outras motivações que não as mesmas do PT. Esse tensionamento fica ainda mais realçado nas demais prefeituras analisadas. Em Contagem, São Bernardo do Campo e São Carlos, os petistas utilizaram as mesmas políticas implementadas em Canoas e Niterói, mas têm mais dificuldades de justificá-las do ponto de vista político. A seguir, é apresentada a visão dos prefeitos e seus secretários sobre a APG.

Duas medidas separam declarações de Jairo Jorge da Silva e de Rodrigo Neves para a pesquisa que embasa este artigo. Em distância, são os 1,1 mil quilômetros entre Canoas de Niterói. No tempo, há um ano e meio de intervalo entre a primeira conversa do pesquisador com o prefeito da cidade sul-rio-grandense, em setembro de 2013, e a entrevista com o prefeito do município fluminense, em março de 2015. Diante de questionamentos sobre suas gestões, ambos utilizaram uma mesma frase célebre para sustentar as políticas estranhas ao petismo tradicional: "Não importa se o gato é branco ou preto; desde que cace os ratos, é um bom gato."

A sentença foi cunhada em 1962 por Deng Xiaoping (1904-1997), secretário-geral do Partido Comunista Chinês, em defesa de reformas econômicas pró-capitalistas no país que se tornaria uma das maiores potências do mundo. Meio século depois, a máxima do líder comunista serviu para sustentar a adesão de petistas à agenda da APG. O pragmatismo sinalizado por Silva e Neves não é desprovido de fundamentação política. Ambos embasam suas escolhas em um discurso articulado e dotado de sentido, ainda que não represente a constituição de um movimento organizado dentro do PT.

A teoria chinesa do gato surge na conversa no momento em que Silva explica que o administrador público não deve ter preconceitos. "Deng Xiaoping tem aquela célebre frase sobre a cor do gato. Temos de ter pragmatismo, um sentido prático, mas não pode ser desprovido de um projeto ideológico, de um sentido estratégico, o que é o grande problema do pragmatismo", diz o prefeito de Canoas. O petista ressalta que há uma "missão", um projeto a ser preservado. "Não podemos perder o projeto, senão fica tudo igual. Não podemos perder o sentido estratégico, mas não podemos ter preconceito", completa. 
Em poucas frases, Silva passa de Xiaoping para Osborne e Gaebler (1994), autores de um dos livros clássicos do gerencialismo. Nas palavras do prefeito, "são dois grandes pensadores da reinvenção do governo que gerou um caldo de cultura para a reforma do Estado e modernização no Brasil”. "Osborne e Gaebler dizem algo muito interessante: a disputa não é ser mais ou menos governo, é ser melhor governo. Acho que esse desejo da sociedade é legítimo, as pessoas querem um governo melhor, que seja mais eficiente, eficaz e efetivo", acrescenta o petista, que se sente parte de uma mudança geracional dentro do PT. Diante das demandas populares, essa nova geração de líderes está buscando inovar e buscar alternativas para os problemas cotidianos da gestão. "O ideário petista dos anos 1970 precisa ser renovado, é necessário construir uma nova agenda política, que esteja sintonizada com temas e atitudes que não faziam parte da ação política no início dos anos 1990", afirma.

Confrontado pela divergência entre o "caldo de cultura" e a posição do PT à época da reforma proposta por Bresser-Pereira, Silva reconhece que houve "incompreensões", mas ressalta que não se pode deixar de analisar o contexto histórico do período. O petista lembra que a agenda da APG foi lançada em um momento de hegemonia do neoliberalismo, com o Consenso de Washington ditando a ideia de um Estado mínimo.

Se (a reforma) tivesse sido concebida hoje, talvez tivesse sido recebida de outra forma. Tem outro aspecto: nós nunca tínhamos governado o Brasil. Quando governamos, amadurecemos com essa experiência de administrar uma nação complexa como o Brasil, um país democrático. É fácil governar um país de forma autoritária, onde se impõe um projeto. Difícil é governar na democracia (Silva).

Apesar das ponderações, Silva não deixa de criticar aspectos da reforma do governo Fernando Henrique. As privatizações, sustentadas teoricamente pelo modelo institucional de Estado desenhado por Bresser-Pereira, são o alvo, embora ele faça uma ressalva: "Não é que eu seja contra as privatizações, às vezes são necessárias. O Estado entrou em áreas que não eram sua função. Algumas privatizações eram necessárias e outras, não.” Para o petista, o problema principal é que esse processo foi imposto pela gestão tucana sem diálogo, aumentando as desconfianças. "Houve outros interesses (em privatizações), que não são públicos. Não quero fazer juízo, não vou discutir se houve desvios ou não, mas isso não pode ser deixado de lado. Quando não há uma concertação, participação da sociedade, isso se junta com os aspectos negativos", completa.

Mesmo que a maioria petista mantenha uma posição crítica construída "em cima de outro tempo político e não desprovida de suas razões", não interessa ao prefeito sustentar uma barreira intransponível entre o PT e a APG. Silva afirma que Bresser-Pereira é "uma das grandes cabeças desse país", mas não basta hoje apenas reproduzir o que o ex-ministro fez na década de 1990: "Em minha opinião, esta é a grande responsabilidade da minha geração: como avançar na gestão sob um olhar 
de esquerda. É fácil dizer não, difícil é propor. É fácil dizer que algo é ruim, mas o que vem no lugar?”.

Achamos que um outro mundo é possível, agora temos de dizer que mundo é esse. Não basta dizer que o mundo que o capitalismo financeiro e o neoliberalismo nos ofereceram é insuficiente. Precisamos construir e mostrar esse outro mundo. E isso exige muito mais de nós, da esquerda, do que exigiu no passado. Hoje, o mundo é mais complexo, tem problemas novos que exigem novas soluções. Não basta reproduzirmos a receita de 1917 ou de outras épocas. Não é suficiente mais isso (Silva).

A solução passa pela recuperação da tradição inovadora da esquerda. "Não podemos perder isso, seria perder a própria essência da esquerda. Em toda a história, Norberto Bobbio nos mostra isso, o progresso, o evento inovador, veio da esquerda, isso é a marca da esquerda", afirma. A proposta está relacionada à posição assumida pela esquerda nos anos de hegemonia neoliberal. Nas décadas de $1980 \mathrm{e}$ 1990, esse campo político ficou acuado, em uma postura reativa, disposta a assegurar a manutenção de direitos. "Mas essa conservação de direitos, que é legítima, não pode nos tirar o aspecto da inovação, da criatividade e da inventividade. Temos de olhar, sim, para onde for, o setor privado, o terceiro setor, em busca de ideias generosas e importantes que nos permitam buscar a eficiência, a eficácia e a efetividade", diz Silva, ressaltando que a esquerda não pode ser "neoludista".

A abertura a técnicas e ferramentas desenvolvidas no mundo empresarial só não pode tropeçar em uma confusão de papéis. Enquanto a iniciativa privada persegue a eficiência e a eficácia para fomentar o lucro, o setor público tem de estar preocupado com a efetividade das políticas. De nada serve ao Estado ser eficiente e eficaz se não produzir resultados conectados às demandas da sociedade. "Não basta ter uma contabilidade em que os dados fecham, essa letra fria não resolve. Quero saber se o dinheiro público está sendo bem empregado para melhorar a vida das pessoas", alerta Silva. Para ilustrar esse raciocínio, ele gosta de repetir uma espécie de mantra: "O setor público tem de ser eficiente, fazer o certo; ser eficaz, fazer o certo, do jeito certo; e ser efetivo, fazer o certo, do jeito certo, para o objetivo certo". Usando jargões do mercado, o petista ressalta ainda que recai sobre o poder público a responsabilidade de atender um usuário que é, ao mesmo tempo, seu "acionista e cliente".

Ao mesmo tempo, a nova geração de administradores petistas tem de ser capaz de enxergar um mundo em transformação, que vai mudar radicalmente a política nos próximos anos. De um lado, a onda de manifestações que varreu o planeta nos últimos anos, inclusive no Brasil, sinaliza para um cidadão que busca participação. "Quem acha que os protestos de 2013 foram um movimento de direita ou de esquerda não entendeu nada. Esquerda e direita participaram como tantos outros, foram atores secundários como outros. $\mathrm{O}$ ator principal são pessoas que querem mais e melhor", analisa. De outro, surge uma nova dimensão laboral, "um mundo 
sem empregos, um mundo de empreendedores, um mundo em que as pessoas são protagonistas do seu destino e de seu futuro".

A multidão é feita por sujeitos autônomos e não por uma massa. São sujeitos que interagem, e o sujeito coletivo é a expressão de milhões. A grande crítica para o período totalitário, seja o socialismo real ou o fascismo, era a existência de uma multidão amorfa, conduzida. Hoje, a multidão é uma inteligência coletiva que é o somatório de milhões de inteligências. É um tempo novo, e cabe à esquerda entender o que está em curso e ser criativa (Silva).

O poder público tem de ser capaz de captar a opinião dos cidadãos para permitir que as políticas sejam direcionadas a atender a vontade das pessoas. "Os indivíduos estão conectados, têm acesso à informação e emitem e compartilham seus juízos sobre a cidade e a gestão. O grande desafio da atualidade é nos conectarmos com a população e transformar o cidadão de demandante em cogestor", diz Silva. Se no século passado a tarefa principal era a universalização dos serviços públicos, hoje é preciso personalizá-los. "Para isso, são fundamentais novas ferramentas de gestão. A população quer resultados, e só os alcançamos se investirmos no aprimoramento das ferramentas administrativas."

Silva é cauteloso ao propor a reformulação do ideário petista que nasceu no final da década de 1970. Ressalta que o PT foi criado de baixo para cima, algo incomum no Brasil, e foi fundamental para impedir a consolidação da ideia de fim da história a partir do fortalecimento do neoliberalismo. "Respeito a tradição e me orgulho das conquistas do PT. Temos de fazer o novo de novo, renovar a partir da tradição", diz o prefeito. E completa: "Temos de nos recriar sem perder a essência. Não somos um partido da ordem nem podemos nos transformar nisso. Temos de ser o partido da mudança, da transformação, da criatividade, da inovação.”

Silva sugere como plataforma uma "gestão focada no cidadão". Essa proposta reúne a radicalização da democracia e o foco na gestão. Em relação ao primeiro eixo, o prefeito afirma que é dever da esquerda erguer a bandeira da democracia porque os setores conservadores já não defendem esse ideal como no passado. "Ninguém questiona que os produtos estão sendo feitos na China, um país sem democracia, governado por um regime autoritário. As empresas não questionam isso, fazem seus produtos lá”, alerta.

No segundo eixo, enquadra-se a ideia de reformar e modernizar a máquina administrativa tendo como meta a resolutividade, resultados para a população. Silva diz que é preciso incentivar inovações que possam levar eficiência, resolutividade e economicidade ao serviço público, com ética, transparência e aderência dos cidadãos. "Se nós defendemos o Estado, temos de ser muito mais zelosos com a gestão. É contraditório: alguns setores defendem o Estado mas são ineficientes e negligentes na gestão do Estado. Isso leva à desconstituição do papel do Estado", argumenta ele. 
Houve um choque de participação a partir de 1989, quando o PT assumiu prefeituras, e teve também um choque de gestão a partir de administrações do PSDB. De fato, é algo bem real. Agora, precisamos de uma terceira onda na visão do Estado. Participação sem gestão pode levar ao populismo. E gestão sem participação pode levar à tecnocracia. Ambos caminhos são improdutivos, nos levam a crises (Silva).

Na conversa com Rodrigo Neves, a frase de Deng Xiaoping surgiu no momento em que o prefeito de Niterói explicava o contrato com uma OS para administrar o Hospital Municipal Infantil Getúlio Vargas Filho. À época da assinatura da parceria, o petista foi acusado por correligionários e sindicatos do serviço público de privatizar a unidade usando uma figura jurídica criada no governo Fernando Henrique. Neves afirma que a solução encontrada para o hospital fez parte de uma estratégia maior para manter a gratuidade, a universalidade e a qualidade de serviços exigidas pelo SUS.

A argumentação do prefeito de Niterói também repete outro pressuposto levantado por Silva, o de que não pode haver preconceito na administração pública. Tratando do uso de técnicas desenvolvidas na iniciativa privada, ele ressalta que "o compromisso da esquerda é com a igualdade de oportunidades e com a garantia de direitos básicos e de cidadania para todos". Se ferramentas do setor empresarial, adaptadas para a esfera pública, podem auxiliar na concretização desses objetivos, então Neves não vê problemas em implantá-las. "Não deve haver preconceitos para aproveitar essas experiências e instrumentos de gestão para melhorar a performance ao setor público", afirma.

Na Niterói de Neves, as ações da prefeitura são construídas, no plano teórico, para dar respostas a duas crises da democracia contemporânea, uma de representatividade e outra de desempenho. A primeira tem um pano de fundo político e, no Brasil, agrava-se em uma dimensão macro, com a sucessão de escândalos envolvendo desvios de recursos públicos e financiamento eleitoral. Esse cenário amplia o fosso entre cidadãos e seus representantes eleitos e provoca a descrença no sistema político. No plano municipal, esse fenômeno se expressa em desconfiança na capacidade de a prefeitura dar soluções aos problemas cotidianos da cidade.

A segunda crise está relacionada à dificuldade do poder público em atender às demandas sociais. "Com o advento das ferramentas de comunicação e de participação, a sociedade demanda cada vez mais e cada vez mais é exigente em relação à execução de projetos do poder público", diz Neves. Por mais que tente reagir à velocidade da informação e da comunicação, porém, a máquina estatal esbarra em limitações, não apenas fiscais. "A própria democracia criou mecanismos necessários de controle da gestão do Estado extremamente rigorosos e que são necessários”, ressalta o prefeito, citando os órgãos de controle, como Ministério Público e Tribunal de Contas, e legislações restritivas à celeridade das ações, como o regramento ambiental. "Há um descompasso entre a demanda da sociedade e a reduzida capacidade de resposta dos governos. Acredito que essa crise, chamada de crise de 
desempenho pelo filósofo Norberto Bobbio, é um dos sintomas mais complexos dos problemas da democracia no Brasil", analisa.

As respostas do petista a esses dois fenômenos estão baseadas em duas estratégias. À crise da demanda social, a saída é ampliar a participação popular. "É preciso ouvir a sociedade sistematicamente e recontratualizar suas metas e compromissos permanentemente com ela", diz Neves. Foi por esse motivo que um planejamento estratégico com horizonte em 2033 foi elaborado com participação da comunidade. A visualização de um futuro dimensiona no tempo o esforço a ser realizado para atingir determinado objetivo e oferece ao cidadão a perspectiva de que há etapas a serem superadas em um cenário de escassez de recursos. "É impossível atender todas as demandas no prazo de um mandato. É fundamental ter sentido de urgência, mas, ao mesmo tempo, pactuar e hierarquizar prioridades ouvindo a sociedade”, ressalta ele. A prefeitura de Niterói também investe no contato com a comunidade por meio de redes sociais.

À crise de desempenho, a resposta é modernizar a administração para dotar a prefeitura de instrumentos que permitam dar celeridade ao processamento das demandas populares e resolver os problemas urbanos. "A modernização da gestão está longe de ser uma agenda colocada na pauta pelos neoliberais. É uma agenda inadiável e estratégica para aqueles que têm compromisso com o fortalecimento da democracia no Brasil”, afirma o prefeito.

Gosto e me orgulho de fazer política, mas apenas a política é muito insuficiente para dar conta da administração de uma cidade. É fundamental estruturar instrumentos e ferramentas de gestão que não são um fim em si mesmo, mas que devem ser aprimorados e desenvolvidos para a boa execução das políticas públicas. Na maioria das administrações que observo, é muito difícil uma boa síntese entre a técnica, a gestão e a política. Acredito que em Niterói estamos buscando construir um caminho no campo progressista para uma boa síntese (Neves).

Questionado sobre o discurso petista antirreforma, o prefeito reconhece que "há um longo caminho a ser percorrido pela esquerda no que diz respeito à modernização da gestão pública". E não se trata de um trajeto sem sinais de urgência, até mesmo para a manutenção do sucesso eleitoral da sigla. O processo de mobilidade social impulsionado pelos governos Lula e Dilma, com a ascensão de milhões de pessoas à classe média, está ampliando o grau de exigência em relação a políticas públicas.

Tem muito a ver com o futuro do PT a nossa capacidade de reinventar a agenda da administração pública em governos progressistas, até mesmo em função do aumento do nível de exigência da população, que foi promovido pelo próprio PT. Esse é um dos desafios e dilemas que temos para o futuro. Tenho 38 anos e faço parte de uma geração de lideranças 
e quadros e gestores do PT que vai reforçar essa agenda no partido e na sociedade (Neves).

As outras administrações estudadas encontram outras formas de explicar a relação com a APG, ainda que todas tenham implementado, com diferentes graus de adesão, instrumentos gerenciais ao longo do mandato. Trata-se de uma evidência da força da polarização entre PT e PSDB. Em Contagem, a ex-prefeita Marília Campos afirma que só há antagonismo entre modernização da gestão e participação popular quando o foco do poder público deixa de ser o cidadão - principalmente aquele que precisa do apoio estatal para recuperar sua dignidade - e passa a ser o mercado. Para ela, as agremiações de esquerda "criam e usam ferramentas de gestão adequadas aos seus propósitos inclusivos, desenvolvimentistas e redistributivos". Por outro lado, "a social-democracia e o neoliberalismo criam e usam ferramentas de gestão adequadas a seus propósitos privatistas e focados no mercado”.

Ex-secretária de Planejamento e Coordenação Geral de Contagem, Eugenia Bossi Fraga reforça os argumentos da ex-chefe. O que separa petistas e tucanos é a ideologia e não técnicas de gestão. Entre os primeiros, a atenção está voltada a políticas públicas universais, e, entre os tucanos, vigora a concepção de um Estado mínimo e regulador.

Qual o problema que vejo a partir da minha experiência em Minas: é você fazer a gestão pela gestão. Fui fazer o mestrado na escola de governo de onde saíam os gestores do Estado, o modelo de gestor do PSDB. Vi que, para essas pessoas, a gestão é maior do que a política. Você fica com uma obsessão pelo modelo. É um negócio engraçado. O modelo de gestão é muito maior do que o resultado dele. [...] Estudei com esse pessoal, acompanho esse pessoal, eles têm uma obsessão pelo modelo. Estão mais preocupados com a eficiência do modelo. Tenho 50 anos e há muitos anos trabalho no serviço público. Para quem executa políticas, o ideal é ser eficaz e eficiente, mas tem hora que a política exige que você seja eficaz. A forma como você faz, avalia depois. Para quem está na ponta, no município, tem de estar muito focado no resultado (Fraga).

Em São Carlos, o ex-prefeito Oswaldo Duarte igualmente levanta o argumento de que o PT coloca a prioridade no atendimento à população, agindo com transparência e abertura ao diálogo. "Não vejo problema em implementar processos modernizantes na administração pública. Aliás, ganhei vários prêmios por aumentar a eficiência na administração associada à transparência e melhorias no atendimento às demandas da sociedade", afirma Duarte. Mas, perguntado sobre a relação dessas posições na disputa com o PSDB, o ex-prefeito menciona um novo elemento explicativo:

Uma coisa é o posicionamento na hora do debate político. Em determinados momentos, você pode se posicionar contrário à determinada questão, mas isso não significa que, no futuro, não possa rever aquele 
posicionamento. Isso acontece o tempo todo e em qualquer partido. Há coisas que o PSDB defendia e hoje joga pedra (risos). A mesma coisa acontece com o PT. Isso faz parte do processo político. Isso não vai sumir, vai acontecer sempre. O grande mérito do PT é o foco que coloca na administração, o foco na solução dos problemas da sociedade. Prefiro pensar em como melhorar a qualidade de vida das pessoas (Duarte).

No berço sindical e político do ex-presidente Lula, São Bernardo do Campo, a polarização entre PT e PSDB encontra seu grau mais elevado entre as administrações pesquisadas. Diante de questionamentos relacionados ao gerencialismo, as declarações do prefeito Luiz Marinho são mais reativas e representam um contraponto às posições externadas por Silva e Neves. Marinho diz ser necessário tomar cuidado com consultorias privadas detentoras de "propostas mágicas". No embalo da crítica, condena "o mito de que no serviço público não existem bons gestores. Não é verdade, temos bons gestores no serviço público e temos péssimos gestores do mundo privado". O prefeito também afirma que executivos do setor privado na máquina estatal podem representar "um desastre porque é outra realidade, outra lógica”.

Tem gente do setor privado que quer fazer as coisas do jeito que está acostumado a fazer na sua empresa e esquece que tem Tribunal de Contas e Ministério Público. Tem a Lei n. 8.666 (Lei das Licitações) que o privado não precisa seguir. Essa lei é um regramento que carece de inteligência. Muitas vezes, você não consegue contratar pelo melhor preço. Contrata pelo menor, e menor preço não é necessariamente o melhor preço. Estamos cansados de ver empresas que ganham licitação, não conseguem fazer o serviço, você tem de interromper, perde tempo, e depois acaba saindo mais caro. Era melhor contratar pelo melhor preço, um pouco mais caro, mas de empresa que garantisse qualidade, prazo e entrega. Falta coisa para ser ajustada na Lei das Licitações. Mas quem for da iniciativa privada e não observar isso vai quebrar a cara (Marinho).

Informado de que o prefeito de Niterói usa a expressão "choque de gestão", Marinho afirma que evita esse slogan porque foi apropriado pelo PSDB e resulta em "muita propaganda nisso e pouca efetividade".

O que Lula fez senão um choque de gestão? O PSDB se apropriou desse slogan. Agora, na gestão do PSDB em São Paulo tem choque do atraso, do marasmo, da lentidão. No debate teórico, eles falam que são bons de gestão e que estão cuidando das pessoas. Veja a crise hídrica em São Paulo e a ausência de planejamento e de execução do planejamento. [...] Há muita propaganda nisso e pouca efetividade. O PT, às vezes, evita alguns chavões, como choque de gestão. Mas estamos fazendo uma grande mudança na gestão pública do país. Lula teve a grande responsabilidade de provocar mudanças significativas em vários segmentos da gestão. O cho- 
que de gestão do PSDB na educação foi tirar o ensino técnico do governo e passar para os estados, e em muitos lugares foi sucateado. Quantas universidades federais Fernando Henrique fez? A do Tocantins, que foi Lula que terminou. Quantas universidades Lula fez? O que é choque de gestão? (Marinho).

\section{CONSIDERAÇÕES FINAIS}

Em uma leitura apressada das declarações apresentadas anteriormente, algumas poderiam ser tomadas como uma espécie de conversão ao PSDB. Leituras superficiais podem ser fruto do açodamento, mas também podem significar uma estratégia de quem não quer enxergar para além do maniqueísmo. As gestões aqui analisadas fazem, em diferentes graus, um gesto incomum na política, o de abraçar uma agenda relacionada ao adversário para reelaborá-la em outras bases. Esse engenho discursivo serve, de um lado, para dar uma resposta à dualidade simplista e, de outro, para erguer uma ponte simbólica entre a posição inicial do partido e aquela que agora é desejável alcançar, evitando cair na armadilha da contradição e atenuando os questionamentos internos.

Isso fica evidente em alguns trechos das entrevistas. "É fundamental estruturar instrumentos e ferramentas de gestão que não tenham fins em si mesmos, mas que devem ser aprimorados e desenvolvidos para a boa execução das políticas públicas”, diz Neves. "O que resultará se tivermos déficit zero nas contas públicas e déficit nos serviços? É claro que temos de buscar o equilíbrio fiscal, mas não podemos perder a dimensão pública da nossa ação", explica Silva. Em um artigo publicado no jornal Folha de S.Paulo, o prefeito de Canoas expõe o argumento de forma mais expressiva. Ele afirma que a sua proposta de uma gestão focada no cidadão é um contraponto à direita neoliberal: "No choque de gestão, o cidadão é transformado em mero cliente, e a eficiência e a eficácia são um fim em si mesmas, dissociadas da efetividade. O cidadão, porém, não é um simples consumidor" (Silva, 2015).

Como demonstrado anteriormente, é neste ponto da reflexão que Silva e Neves se encontram com os outros prefeitos. Ainda que todos tenham implantado políticas relacionadas à APG, as formas de explicar a relação com o gerencialismo variam. Há, no entanto, um esforço comum em demonstrar as razões que tornam o uso dessas ferramentas algo singular em gestões petistas. E não poderia ser diferente. $\mathrm{Na}$ construção do embate político em uma democracia, as forças em disputa precisam acentuar diferenças em relação aos adversários e demarcar posições no debate público. O importante aqui é evidenciar que o conteúdo que compõe essa identidade partidária é cambiável. Esses prefeitos petistas absorvem uma agenda associada ao PSDB e a tornam parte de um outro projeto político que não o tucano. 


\section{REFERÊNCIAS BIBLIOGRÁFICAS}

ABRUCIO, Fernando Luiz. (1998) "Os avanços e dilemas do modelo pós-burocrático: a reforma da administração pública à luz da experiência internacional recente”. In BRESSER-PEREIRA, Luiz C.; SPINK, Peter (Orgs.). Reforma do Estado e Administração Pública Gerencial. Rio de Janeiro: Editora Fundação Getulio Vargas.

ABRUCIO, Fernando Luiz.; GAETANI, F. (2008) “Avanços e Perspectivas da Gestão Pública nos Estados: Agenda, Aprendizado e Coalizão”. In COSTA, Luciana Lima. (Org.). Avanços e Perspectivas da Gestão Pública nos Estados. 1 ed. Rio de Janeiro: Editora Qualitymark, v. 1.

ABRUCIO, Fernando Luiz.; PEDROTI, Paula; PÓ, Marcos Vinicius. (2010) “A formação da burocracia brasileira: a trajetória e o significado das reformas administrativas". In LOUREIRO, Maria Rita; ABRUCIO, Fernando Luiz; PACHECO, Regina Silvia (orgs.). Burocracia e Política no Brasil: desafios para a ordem democrática no século XXI. Rio de Janeiro: Editora FGV.

ALVES, Giovanni. (2013) Neodesenvolvimentismo e Estado liberal no Brasil. Blog da Boitempo.

BRESSER-PEREIRA, Luiz Carlos.(1996) "Entrevista para Conversa com Economistas”. In BIDERMAN, Ciro; Luis Felipe Cozac e José Marcio Rego, orgs. Conversas com Economistas, S.Paulo: Editora 34.

BRESSER-PEREIRA, Luiz Carlos. (1998) “Da administração pública burocrática à gerencial”. In BRESSER-PEREIRA, Luiz Carlos; SPINK, Peter (orgs.). Reforma do Estado e Administração Pública Gerencial. Rio de Janeiro: Editora Fundação Getulio Vargas.

BRESSER-PEREIRA, Luiz Carlos (2001) "Uma nova gestão para um novo Estado: liberal, social e republicano”. Revista do Serviço Público, 52 (1), p. 1-16.

BRESSER-PEREIRA, Luiz Carlos.(2008) "O modelo estrutural de gerência pública”. Revista da Administração Pública, Rio de Janeiro, v. 42, n. 2, p. 391-410.

BRESSER-PEREIRA, Luiz Carlos. (2010a) "Os primeiros passos da reforma gerencial do Estado de 1995”. In D’INCAO, Maria Angela; MARTINS, Hermínio (orgs.). Democracia, Crise e Reforma: Estudos sobre a Era Fernando Henrique Cardoso. São Paulo: Paz e Terra.

BRESSER-PEREIRA, Luiz Carlos. (2010b) “Democracia, Estado social e reforma gerencial”. Revista de Administração de Empresas, São Paulo, v. 50, n. 1, p. 112-116.

BRESSER-PEREIRA, Luiz Carlos. (2014) A Construção Política do Brasil: Sociedade, economia e Estado desde a Independência. São Paulo: Editora 34.

BRESSER-PEREIRA, Luiz Carlos. (2017) “Reforma gerencial e legitimação do Estado social”. Revista de Administração Pública, Rio de Janeiro, n. 51 (1), p. 147-156.

DASSO JÚNIOR, Aragon Érico. (2006) "O déficit democrático da reforma ultraliberal do Estado brasileiro”. In XI Congreso Internacional del CLAD sobre la Reforma de Estado y de la Administración Pública, Ciudad de Guatemala, 7-10 novembro.

FERLIE, Ewan; ASBURNER, Lynn; FITZGERALD, Louise; PETTIGREW, Andrew. (1999) A nova administração pública em ação. Brasília: Editora Universidade de Brasília: ENAP.

FERRAREZI, Elisabete R. (2007) "A reforma do marco legal do terceiro setor no Brasil: a criação da Lei das Oscips (Lei 9.790)”. Tese (Doutorado em Sociologia) - Instituto de Ciências Sociais, UnB, Brasília, 2007.

GENRO, Tarso. (2012) Explorando os limites de uma esquerda reformada. 2 de jan. 2012. Disponível em: <http://www.rsurgente.opsblog.org>.

GUGLIANO, Alfredo A. (2005) "O impacto das democracias participativas na produção acadêmica no Brasil: teses e dissertações (1988-2002)”. BIB, n. 59, pp. 43-60.

JANN, Werner; REICHARD, Christoph. (2002) “Melhores práticas na modernização do Estado". Revista do Serviço Público, ano 53, n. 3, p. 33-49.

LACLAU, Ernesto; MOUFFE, Chantal. (1985) Hegemony and socialist strategy: towards a radical democratic politics. London: Verso.

MANIFESTO DO PT. Documentos Dossiê. N. ${ }^{\circ}$, Ano I, 2007. Disponível em: <http://www.fpabramo. org.br/sites/default/files/P1_Dossie\%20Doctos.pdf>.

MARE. Plano Diretor da Reforma do Aparelho do Estado. Brasília: Presidência da República, Impren- 
sa Oficial, 1995. Disponível em: <http://www.bresserpereira.org.br/documents/mare/planodiretor/planodiretor.pdf>.

MARTINS, Humberto Falcão. (1997) "Burocracia e a revolução gerencial: a persistência da dicotomia entre política e administração". Revista do Serviço Público, ano 48, n. 1, p. $42-78$.

MARTINS, Humberto Falcão; MARINI, Caio; DUARTE, Kênnya; LEMOS, Carolina. (2006) "Acordo de resultados”. In: VILHENA, Renata; MARTINS, Humberto Falcão; MARINI, Caio; GUIMARÃES, Tadeu B. (orgs.). O Choque de Gestão em Minas Gerais: Políticas da gestão pública para o desenvolvimento. Belo Horizonte: Editora UFMG.

MATTOS, Pedro Lincoln C. L.; SIQUEIRA, Maria Eliza G. (2008). "Consultoria externa em reforma do Estado tem função técnica ou estratégica? Um estudo de caso”. Revista da Administração Pública, Rio de Janeiro, v. 1, n. 42, p. 35-60.

MERCADANTE, Aloizio. (2010) "As bases do novo desenvolvimentismo no Brasil: análise do governo Lula (2003-2010)”. Tese (Doutorado) - Instituto de Economia/Unicamp, Campinas.

OLIVEIRA, Francisco. (2007) "Hegemonia às avessas". Revista Piauí, n. 4.

OSBORNE, David; GAEBLER, Ted. (1994) Reinventando o Governo: Como o Espírito Empreendedor está transformando o Setor Público. 2. ed. Brasília: MH Comunicação.

PACHECO, Regina Silvia. (2010) “A agenda da Nova Gestão Pública”. In: LOUREIRO, Maria Rita; ABRUCIO, Fernando Luiz; PACHECO, Regina Silvia (orgs.). Burocracia e política no Brasil: desafios para a ordem democrática no século XXI. Rio de Janeiro: Editora FGV.

PARTIDO DOS TRABALHADORES. Estatuto. Atualizado em 12 de dezembro de 2013. Disponível em: <https://www.pt.org.br/wp-content/uploads/2014/04/ESTATUTO_PT_2012_-_VERSAO_FINAL_registrada.pdf>.

RIBEIRO, Pedro José Floriano. (2008) "Dos sindicatos ao governo: a organização nacional do PT de 1980 a 2005”. Tese (Doutorado) - UFSCar, São Carlos.

SILVA, Jairo Jorge da. (2015) "Radicalizar a democracia". Folha de S.Paulo, São Paulo, 24 fevereiro.

SINGER, André. (2012) Os Sentidos do Lulismo: reforma gradual e pacto conservador. São Paulo: Cia das Letras. 